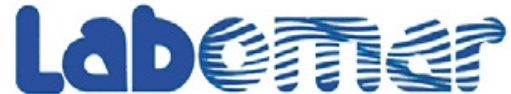

Arquivos de Ciências do Mar

\section{LEGISLAÇÃO BRASILEIRA APLICADA AO AQUARISMO MARINHO: A TORRE DE BABEL ORNAMENTAL}

\author{
Brazilian legislation applied to marine aquarium trade: \\ The Ornamental Tower of Babel
}

\author{
Lívio Moreira de Gurjão \\ ${ }^{1}$ Analista Ambiental, Núcleo de Biodiversidade e Florestas da Superintendência do Ibama no Ceará, Av. Visconde do Rio \\ Branco, 3900, Joaquim Távora, CEP 60055-172, Fortaleza-CE, Brasil. E-mail: livio.gurjao@gmail.com
}

\begin{abstract}
RESUMO
Nos últimos anos foram realizadas muitas mudanças na gestão pública e na legislação brasileira aplicada à utilização de espécies no aquarismo marinho. Entretanto, várias dessas pouco contribuíram para a gestão dos recursos pesqueiros e, em alguns casos, só serviram para deixar a situação ainda mais confusa. A criação, transformação e extinção de entidades públicas, além do repasse frenético de competências entre elas fragilizou a autoridade dessas instituições, promovendo dificuldades administrativas e operacionais relativas à gestão da explotação de espécies usadas no aquarismo marinho. Essas mudanças desastrosas culminaram com um ambiente de extrema instabilidade, especialmente em relação à existência de hiatos temporais de ausência completa dos efeitos de listas nacionais de espécies ameaçadas de extinção, o que é bastante prejudicial para a conservação das espécies brasileiras usadas no aquarismo marinho. Se faz urgente a definição de um planejamento para a gestão dos recursos pesqueiros no país, com metas bem estabelecidas a curto, médio e longo prazo.
\end{abstract}

Palavras-chaves: Aquarismo marinho, peixes ornamentais marinhos, invertebrados marinhos, espécies ameaçadas, leis brasileiras, governo brasileiro, ordenamento legal.

\section{ABSTRACT}

Recently, many changes were performed regarding Brazilian public management and legislation applyed to marine aquarium species. However, much of them had little contribution to fishery

Recebido em: 22/06/2017

Aprovado em: 07/12/2017

Publicado online em: 05/09/2018 
management and, in some cases, made the situation even more confusing. The creation, transformation and extiction of public entities, besides the frenetic transference of reponsabilities among them weakend the authority of these institutions, causing managing and operational dificulties concerning the exploitation of marine aquarium species. Such unfortunate changes resulted in an extremely unstable environment, specially regarding transitory suspension of the effects of national lists of threatened species, which is very dangerous for the Brazilian marine aquarium species conservation. It is urgent the definition of a management plan for fishery resources in the country, with clearly established short, medium and long term goals.

Keywords: Marine aquarium trade, marine ornamental fish, marine invertebrates, threatened species, Brazilian laws, Brazilian government, regulatory framework.

\section{INTRODUÇÃO}

A explotação mundial de espécies ornamentais marinhas movimenta milhões de dólares anualmente e envolve a comercialização de bilhões de indivíduos pertencentes a mais de 150 espécies de corais duros, centenas de outros invertebrados e pelo menos 1.800 espécies de peixes recifais (Wabnitz, 2003; Whittington \& Chong, 2007; Rhyne et al., 2014; Leal et al., 2016).

O Brasil vem sendo apontado como um grande abastecedor do mercado mundial de peixes ornamentais marinhos (Wood, 2001; Bruckner, 2005). Entretanto, assim como nos outros países exportadores, a grande maioria das espécies comercializadas provem de coletas na natureza, o que tem acarretado preocupações acerca da sustentabilidade dessa atividade no país (Monteiro-Neto et al., 2003; Gasparini et al., 2005; Nottingham et al., 2005).

A fim de promover o ordenamento do uso sustentável das espécies na aquariofilia marinha, nos últimos anos foram realizadas mudanças na gestão pública e na legislação voltada para esse setor (Nottingham et al., 2005; Sampaio \& Nottingham, 2008). Entretanto, essas não se mostraram eficazes para o ordenamento pesqueiro (Rosa et al., 2011; Sampaio \& Ostrensky, 2013; Magalhães, 2015) e, pelo contrário, em alguns casos só serviram para deixar todo o cenário muito mais confuso.

\section{ALTERAÇÕES NA LEGISLAÇÃO BRASILEIRA E MUDANÇAS ESTRUTURAIS NA ADMINISTRAÇÃO PÚBLICA}

Até o final da década de 1990, a gestão do uso de recursos pesqueiros no Brasil, no âmbito federal, era atribuição do Ministério do Meio Ambiente - MMA e do Instituto Brasileiro do Meio Ambiente e dos Recursos Naturais Renováveis - IBAMA. Porém, com a publicação da Lei Federal n ${ }^{\circ}$ 9.649/98 (Brasil, 1998a), parte das competências foram repassadas para o Ministério da Agricultura, Pecuária e Abastecimento - MAPA, o qual, através de seu Departamento de Pesca e Aquicultura-DPA, assumiu a responsabilidade pela produção e fomento da pesca no país, organização e manutenção do Registro Geral de Pesca - RGP, concessão de licenças, autorizações e permissões para exercício da pesca e aquicultura, entre outros.

Posteriormente, com a publicação da Lei Federal n 10.683/03 (Brasil , 2003), restou criada a Secretaria Especial de Pesca e Aquicultura da Presidência da República - SEAP/ 
PR, cujas atribuições passaram a ser aquelas relacionadas à aquicultura e pesca, anteriormente delegadas ao MAPA (Nottingham et al., 2005).

Quatro anos depois, a Lei Federal $n^{\circ}$ 11.516/07 (Brasil, 2007) criou o Instituto Chico Mendes de Conservação da Biodiversidade-ICMBio, o qual passou a ser a instituição responsável pela gestão e fiscalização da exploração de recursos naturais no interior de unidades de conservação-UCs federais (Sátyro, 2008). Desse modo, as ações do IBAMA relativas à gestão e fiscalização da captura e cultivo de peixes ornamentais marinhos ficaram restritas ao exterior das UCs.

Outra distinção importante entre a atuação dessas duas autarquias se deu com relação ao propósito do uso de recursos naturais coletados. Por exemplo, se a coleta de organismos tem como objetivo a pesquisa científica no Brasil, compete ao ICMBio, por meio do SISBIO (Portaria MMA n² 236/08) (Brasil, 2008a) autorizar ou não a realização de capturas. No entanto, se os organismos coletados forem enviados para instituições de pesquisa no exterior, uma autorização de exportação deve ser obtida junto ao IBAMA. Por outro lado, se as coletas de espécies decorrerem de estudos ambientais no âmbito do licenciamento ambiental federal, compete ao IBAMA, e não ao ICMBio, autorizá-las. Porém, se essa coleta relativa ao licenciamento englobar área de UC federal, faz-se necessária a obtenção de uma anuência do ICMBio, além da permissão do IBAMA.

Essa cisão e repartição esdrúxula de competências, ao invés de fortalecer a área ambiental, fez com que tanto o IBAMA como o ICMBio ficassem desestruturados e, apesar de legalmente separados, tiveram que trabalhar de maneira conjunta (Acordo de Cooperação $n^{\circ}$ 19/2007) por alguns anos, até que ambos pudessem minimamente se adaptar à nova configuração imposta.

Poucos anos depois, a SEAP/PR foi transformada em Ministério da Pesca e Aquicultura - MPA pela Lei Federal n 11.958/09 (Brasil, 2009a) e a ele coube, em conjunto com o MMA, mas sob sua coordenação, a gestão compartilhada do uso sustentável dos recursos pesqueiros. Entretanto, mesmo decorridos alguns anos da criação do MPA, foi notório que tanto a coordenação da gestão compartilhada como também as atribuições específicas do MPA não vinham sendo executadas como previsto em lei. Por isso, outras entidades da administração pública tiveram que suprir essas lacunas deixadas pela falta de estrutura. No caso de ações relativas a peixes ornamentais marinhos, por exemplo, as autorizações anuais de exportação e importação previstas na Instrução Normativa IBAMA n 202/08 (Brasil, 2008b) continuaram sendo analisadas e concedidas exclusivamente pelas Superintendências do IBAMA nos estados - ou seja, essas permissões continuaram a ser concedidas através de atos administrativos unilaterais e não de uma gestão compartilhada entre MMA e MPA, como previsto em lei.

Adicionalmente, as responsabilidades do MPA relacionadas à sanidade pesqueira e aquícola, bem como à fiscalização das atividades de aquicultura e pesca (art. 27, XXIV, "e" e "g" da Lei n 11.958/09) (Brasil, 2009a) tiveram que ser supridas, respectivamente, pelo MAPA (Decreto ${ }^{\circ}$ 7.024/09) (Brasil, 2009b) e IBAMA (art. 27, XXIV, §12 da Lei 11.958/09) (Brasil, 2009a), enquanto o novo ministério não era estruturado para assumir tais competências.

Todo esse amontoado de alterações nas instituições responsáveis pela gestão dos recursos pesqueiros no país culminou com a extinção do MPA e com retorno de suas atribuições ao MAPA, por meio da Lei Federal n $n^{\circ}$ 13.266/16 (Brasil, 2016). Posteriormente, as responsabilidades relativas à pesca e aquicultura foram transferidas do MAPA para o Ministério da Indústria, Comércio Exterior e Serviços - MDIC, mediante a publicação do Decreto Federal n ${ }^{\circ}$ 9.004/17 (Brasil, 2017a), e, mais recentemente para a Secretaria Especial da Aquicultura e da Pesca ligada à Secretaria-Geral da Presidência da República, por meio do Decreto Federal n 9.330/18 (Brasil, 2018a) (figura 1). 
Figura 1 - Transferência e repartição de competências na gestão de recursos pesqueiros entre as entidades federais, ao longo dos últimos anos. Instituições públicas federais: Ministério do Meio Ambiente-MMA; Departamento de Pesca e Aquicultura do Ministério da Agricultura, Pecuária e Abastecimento-DPA/MAPA; Instituto Brasileiro do Meio Ambiente e dos Recursos Naturais Renováveis-IBAMA; Secretaria Especial de Aquicultura e Pesca da Presidência da República-SEAP/PR; Instituto Chico Mendes de Conservação da Biodiversidade-ICMBio; Ministério da Pesca e Aquicultura-MPA; Ministério da Indústria, Comércio Exterior e Serviços - MDIC e Secretaria Especial da Aquicultura e da Pesca da Secretaria-Geral da Presidência da República SEAP/SG/PR.

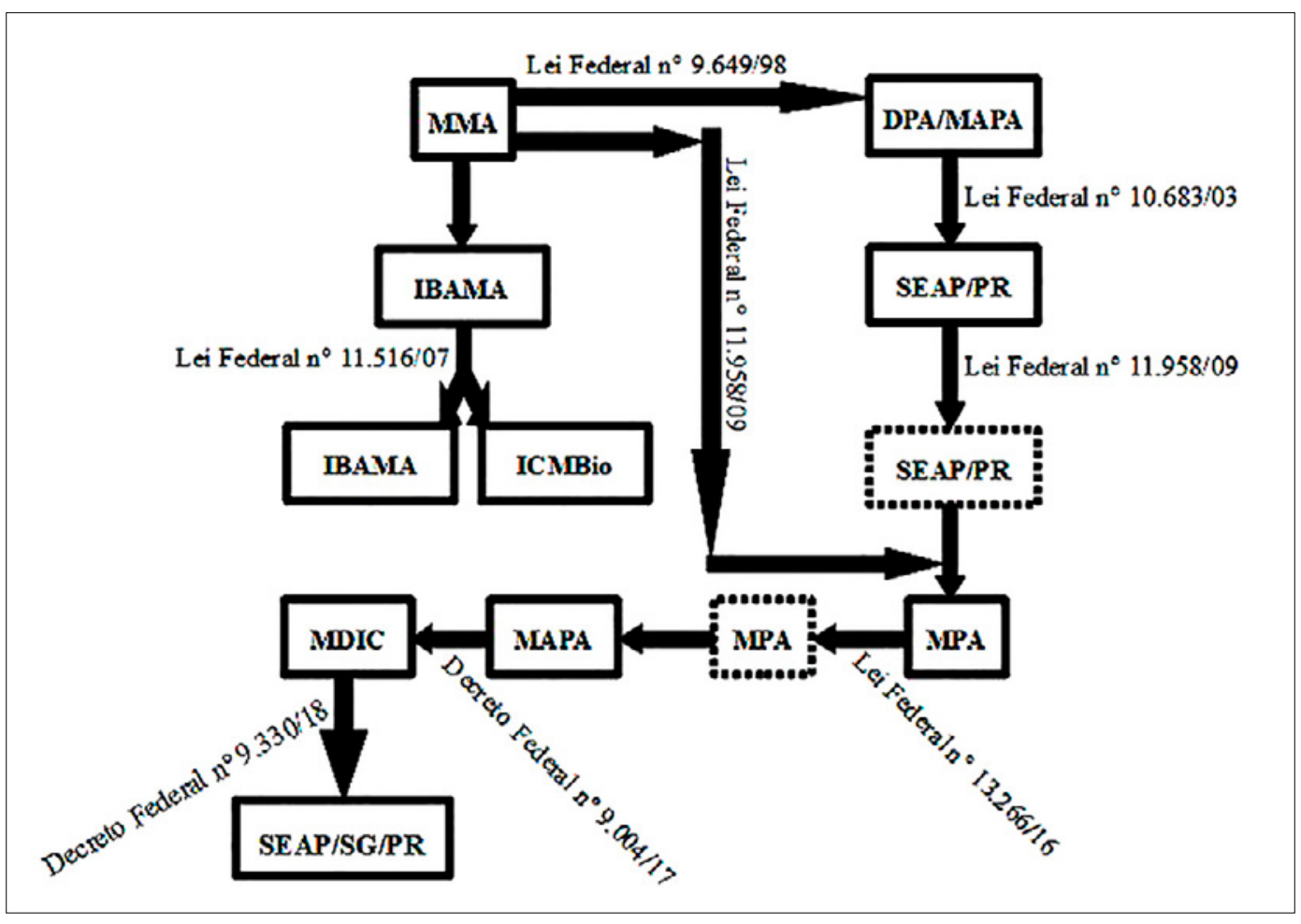

Daí surgem alguns questionamentos: Quem se beneficia com tantas mudanças? O que se almeja com tanta divisão, criação e extinção de entidades públicas? A exemplo do que vem acontecendo no Brasil, no México a existência de várias instituições encarregadas da gestão do uso de espécies no aquarismo marinho pouco contribui para o desenvolvimento sustentável da atividade e tampouco permite preservar os benefícios econômicos e sociais gerados (Reynoso et al., 2012).

Cada mudanças promovida pelo governo exige uma reorganização das instituições envolvidas, além de uma estruturação para se adaptar às novas atribuições delegadas. Isso fragiliza a autoridade de instituições públicas, gerando-lhes dificuldades administrativas e operacionais quanto ao ordenamento da explotação de espécies usadas no aquarismo marinho (Nottingham et al., 2005).

\section{ORDENAMENTO DO USO DOS ORGANISMOS NA AQUARIOFILIA MARINHA E ESPÉCIES AMEAÇADAS DE EXTINÇÃO}

Além das supracitadas modificações estruturais, a legislação brasileira também promoveu mudanças funcionais no sistema de gestão do uso de espécies na aquariofilia marinha. Muitos foram os esforços direcionados para o ordenamento do uso dos peixes (Nottingham et al., 2005a; Brasil, 2008c), mas pouca atenção tem sido dada à utilização de invertebrados (Gasparini et al., 2005; Brasil, 2008d). 
Atualmente a captura, o transporte e a utilização de peixes ornamentais marinhos são regidos pela Instrução Normativa IBAMA n 202/08 (Brasil, 2008b). Este instrumento traz consigo uma lista das espécies nativas que podem ser capturadas e exportadas, além de indicar as espécies exóticas passíveis ou não de importação (Sampaio \& Nottingham, 2008; Sampaio \& Ostrensky, 2013; Magalhães, 2015).

Já para os invertebrados usados no aquarismo marinho, não existe uma legislação específica (Gasparini et al., 2005; Brasil, 2008d). Entretanto, em conformidade com a Lei dos Crimes Ambientais, a captura de moluscos e crustáceos, dentre outros organismos, é tratada como ato de pesca, portanto não susceptível às sanções previstas no $\S 1^{\circ}$, art. 29 da Lei Federal n $n^{\circ} 9.605 / 98$ (vide também $§ 6^{\circ}$ desse mesmo artigo) (Brasil, 1998b), desde que as espécies capturadas não constem em listas oficiais de fauna ameaçada de extinção (Sampaio \& Ostrensky, 2013). Ou seja, o uso dos peixes na aquariofilia marinha deve obedecer às restrições impostas tanto pela IN IBAMA n 202/08 (Brasil, 2008b) como pela Lei Federal n 9.605/98 (Brasil, 1998b), enquanto que o de invertebrados limita-se apenas a esta última.

Com relação às listas nacionais de espécies ameaçadas de extinção, fundamentais para o planejamento e gestão do uso dos recursos naturais (Bender et al., 2012), a situação atual é caótica, justamente em virtude das mudanças estruturais atabalhoadas anteriormente referidas. Desde a década de 1990, as listas oficiais de peixes e invertebrados ameaçados vinham sendo estabelecidas por meio de atos normativos exclusivos do MMA e IBAMA, sem maiores problemas. No entanto, como a mais recente lista de peixes e invertebrados aquáticos ameaçados de extinção adveio de um ato normativo editado exclusivamente pelo MMA (Portaria MMA n 445/14) (Brasil, 2014a), sem a participação do MPA, foi aberto um precedente para se questionar a legalidade dessa regulamentação.

Por meio de ações judiciais, alguns segmentos da sociedade alegaram que como por lei a gestão dos recursos pesqueiros era compartilhada e coordenada pelo MPA, o MMA não poderia editar unilateralmente aquele ato normativo.

Assim, após os questionamentos jurídicos, a Portaria MMA n 445/14 (Brasil, 2014) passou ter seus efeitos suspensos em junho de 2015, depois revalidados em maio de 2016, novamente suspensos em agosto de 2016 e outra vez revalidados em dezembro de 2016 (figura 2). Posteriormente, a Portaria MMA n 445/14 (Brasil, 2014) foi modificada pelas Portarias MMA n 161/17 (Brasil, 2017b), 217/17 (Brasil, 2017c; Brasil, 2017d), 073/18 (Brasil, 2018b) e 129/18 (Brasil, 2018c), as quais alteraram restrições impostas à explotação de alguns peixes utilizados no aquarismo marinho autorizados pela IN IBAMA n² 202/08 (Brasil, 2008b) (Scarus zelindae Moura, Figueiredo \& Sazima, 2001; Sparisoma axillare (Steindachner, 1878); Sparisoma frondosum (Agassiz, 1831); Hippocampus reidi Ginsburg, 1933; Hippocampus erectus Perry, 1810)), além de Scarus trispinosus (Valenciennes, 1840), usado de maneira ilegal nessa atividade (Mohr et al., 2009).

Essa grande confusão de instituições causada pelo Governo Federal, associada à indefinição judicial da validade da Portaria MMA nº 445/14 (Brasil, 2014), além de provocar muita insegurança jurídica, também é bastante danosa para a conservação de espécies nativas usadas na aquariofilia marinha.

A Portaria MMA n 445/14 (Brasil, 2014) revogou as Instruções Normativas MMA n 05/04 (Brasil, 2004) e n 52/05 (Brasil, 2005) (antigas listas de espécies de peixes e invertebrados aquáticos ameaçados de extinção) e com a suspensão dos seus efeitos por ordem judicial, passou a existir, um hiato no que tange à relação de espécies ameaçadas. Ou seja, enquanto os efeitos daquela Portaria estavam suspensos e uma vez que nesse caso o sis- 
tema jurídico brasileiro não admite a repristinação das supracitadas Instruções Normativas, restava constatada, em tese, a inexistência de uma lista nacional de espécies de peixes e invertebrados aquáticos ameaçados de extinção válida no país naqueles momentos.

Figura 2 - Histórico da publicação das listas nacionais contendo espécies de peixes e invertebrados aquáticos ameaçados de extinção.

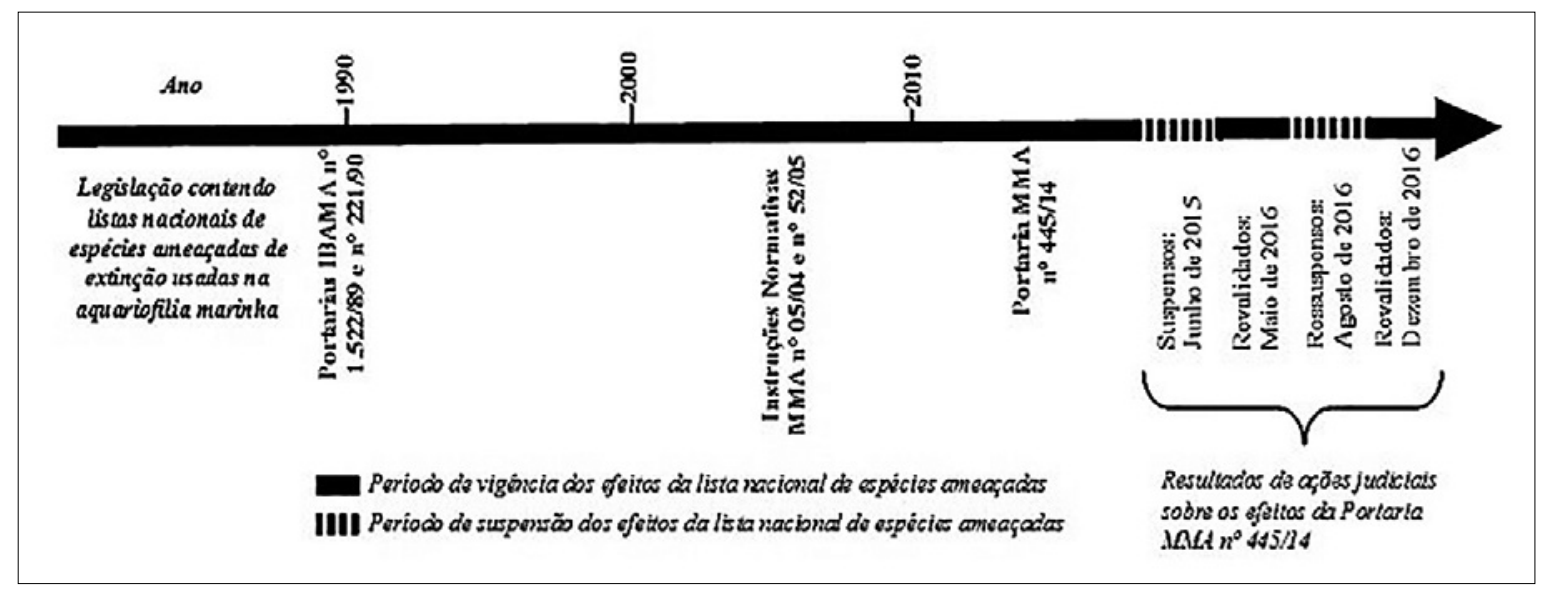

Diante desse cenário de lacuna de listas nacionais de espécies ameaçadas, as sanções aplicadas pelos órgãos de fiscalização ambiental, teoricamente, não mais poderiam ser majoradas em desfavor de infratores que estivessem capturando espécies relacionadas nas Instruções Normativas MMA n⿳0 05/04 (Brasil, 2004) e $n^{\circ}$ 52/05 (Brasil, 2005) ou Portaria MMA n ${ }^{\circ} 445 / 14$ (Brasil, 2014), mas apenas quando os organismos coletados constassem em listas internacionais (ex: the IUCN red list of threatened species) ou estaduais de espécies ameaçadas, quando existentes (Bender et al., 2012) - o que não deixa de ser um estímulo a mais à prática de ilícitos dessa natureza.

\section{CONSIDERAÇÕES FINAIS}

Dificuldades estruturais e normativas para gerir a explotação de espécies ornamentais marinhas são enfrentadas pela grande maioria dos países produtores e consumidores (Tissot et al., 2010; Reynoso et al., 2012; Rhyne et al., 2014; Prakash et al., 2017) e poucas foram as experiências bem sucedidas para monitorar alguns segmentos da atividade (Rhyne et al., 2017).

No Brasil, diante de todo o exposto, é fácil observar que a gestão de recursos pesqueiros, especialmente daquelas espécies utilizadas na aquariofilia marinha, está caótica. Tudo é muito confuso, a sociedade e as instituições públicas não conseguem se entender e estas tentam realizar seus trabalhos em conformidade com o que está previsto em lei, mesmo sem condições de cumprir integralmente com suas obrigações, seja por falta de estrutura física, de recursos humanos ou financeiros.

Por isso, é inconcebível que os gestores públicos mudem de ideia a todo instante e fiquem criando, desmembrando e extinguindo entidades, além de transferir e devolver sucessivamente competências de uma para outra. É urgente que a administração pública se organize e estabeleça um planejamento prévio, com metas bem definidas a curto, médio e longo prazo para a gestão dos recursos pesqueiros no país. 
Agradecimentos - À Daniele Lopes (IBAMA-CE) e aos pareceristas anônimos, cujas sugestões e críticas contribuíram para melhorias no presente trabalho.

\section{REFERENCIAS BIBLIOGRÁFICAS}

Bender, M.G.; Floeter, S.R.; Ferreira, C.E.L \& Hanazaki, N. Mismatches between global, national and local red lists and their consequences for Brazilian reef fish conservation. Endang. Species Res., v. 18, p. 247-254, 2012.

Brasil. Lei n. ${ }^{\circ}$ 9.649, de 27 de maio de 1998. Dispõe sobre a organização da Presidência da República e dos Ministérios, e dá outras providências. Diário Oficial da União, Brasília, DF, 28 mai. 1998. Disponível em: http://www.planalto.gov.br/ccivil_03/leis/L9649cons.htm. Acesso em: 06 nov. 2017. 1998a.

Brasil. Lei $\mathrm{n}^{\circ}$ 9.605, de 12 de fevereiro de 1998. Dispõe sobre as sanções penais e administrativas derivadas de condutas e atividades lesivas ao meio ambiente, e dá outras providências. Diário Oficial da União, Brasília, DF, 13 fev. 1998. Disponível em: http:// www.planalto.gov.br/ccivil_03/leis/L9605.htm. Acesso em: 06 nov. 2017. 1998b.

Brasil. Lei $\mathrm{n}^{\mathrm{O}}$ 10.683, de 28 de maio de 2003. Dispõe sobre a organização da Presidência da República e dos Ministérios, e dá outras providências. Diário Oficial da União, Brasília, DF, 29 mai. 2003. Disponível em: http://www.planalto.gov.br/ccivil_03/leis/2003/L10.683. htm. Acesso em: 06 nov. 2017. 2003.

Brasil. Ministério do Meio Ambiente. Instrução Normativa n 05, de 21 de maio de 2004. Diário Oficial da União, Brasília, DF, 24 mai. 2004. Disponível em: http:/ / www.icmbio.gov. br/portal/images/stories/IN\%2005\%20-\%20peixes\%20e\%20invertebrados.pdf. Acesso em: 06 nov. 2017. 2004.

Brasil. Ministério do Meio Ambiente. Instrução Normativa $\mathrm{n}^{\circ}$ 52, de 08 de novembro de 2005. Diário Oficial da União, Brasília, DF, 09 nov. 2005. Disponível em: http:/ / www.icmbio. gov.br/sisbio/images/stories/instrucoes_normativas/in-52-altera-in-5.pdf. Acesso em: 06 nov. 2017. 2005.

Brasil. Lei $\mathrm{n}^{\mathrm{O}}$ 11.516, de 28 de agosto de 2007. Dispõe sobre a criação do Instituto Chico Mendes de Conservação da Biodiversidade - Instituto Chico Mendes; altera as Leis n ${ }^{\text {OS }}$ 7.735, de 22 de fevereiro de 1989, 11.284, de 2 de março de 2006, 9.985, de 18 de julho de 2000, 10.410, de 11 de janeiro de 2002, 11.156, de 29 de julho de 2005, 11.357, de 19 de outubro de 2006, e 7.957, de 20 de dezembro de 1989; revoga dispositivos da Lei n $\mathrm{n}^{\mathrm{O}}$ 8.028, de 12 de abril de 1990, e da Medida Provisória n⿳2.216-37, de 31 de agosto de 2001; e dá outras providências. Diário Oficial da União, Brasília, DF, 28 ago. 2007. Disponível em: http://www.planalto.gov.br/ccivil_03/_ato2007-2010/2007/lei/111516.htm. Acesso em: 06 nov. 2017. 2007.

Brasil. Ministério do Meio Ambiente. Portaria n² 236, de 08 de agosto de 2008. Diário Oficial da União, Brasília, DF, 11 ago. 2008. Disponível em: http://www.icmbio.gov.br/sisbio/ images/stories/instrucoes_normativas/Portaria236_08.pdf. Acesso em: 06 nov. 2017. 2008a.

Brasil. Instituto Brasileiro do Meio Ambiente e dos Recursos Naturais Renováveis. Instrução Normativa $n^{\circ}$ 202, de 22 de outubro de 2008. Diário Oficial da União, Brasília, DF, 11 ago. 
2008. Disponível em: http://www.icmbio.gov.br/sisbio/images/stories/instrucoes_ normativas/Portaria236_08.pdf. Acesso em: 06 nov. 2017. 2008b.

Brasil. Instituto Brasileiro do Meio Ambiente e dos Recursos Naturais Renováveis. Diagnóstico geral das práticas de controle ligadas a exploração, captura, comercialização, exportação $e$ uso de peixes para fins ornamentais e de aquariofilia. Brasília, 2008c.

Brasil. Instituto Brasileiro do Meio Ambiente e dos Recursos Naturais Renováveis. Relatório da reunião nacional sobre o ordenamento do uso de invertebrados marinhos. Vitória, 2008d.

Brasil. Lei $\mathrm{n}^{\mathrm{O}} 11.958$, de 26 de junho de 2009. Altera as Leis $\mathrm{n}^{\mathrm{OS}} 7.853$, de 24 de outubro de 1989, e 10.683, de 28 de maio de 2003; dispõe sobre a transformação da Secretaria Especial de Aquicultura e Pesca da Presidência da República em Ministério da Pesca e Aquicultura; cria cargos em comissão do Grupo-Direção e Assessoramento Superiores - DAS e Gratificações de Representação da Presidência da República; e dá outras providências. Diário Oficial da União, Brasília, DF, 26 jun. 2009. Disponível em: http:/ / www.planalto.gov. br/ccivil_03/_ato2007-2010/2009/lei/111958.htm. Acesso em: 06 nov. 2017. 2009a.

Brasil. Decreto $\mathrm{n}^{\mathrm{O}} 7.024$, de 07 de dezembro de 2009. Altera as Leis $\mathrm{n}^{\mathrm{OS}} 7.853$, de 24 de outubro de 1989, e 10.683, de 28 de maio de 2003; dispõe sobre a transformação da Secretaria Especial de Aquicultura e Pesca da Presidência da República em Ministério da Pesca e Aquicultura; cria cargos em comissão do Grupo-Direção e Assessoramento Superiores - DAS e Gratificações de Representação da Presidência da República; e dá outras providências. Diário Oficial da União, Brasília, DF, 08 dez. 2009. Disponível em: http://www.planalto.gov.br/ccivil_03/_Ato2007-2010/2009/Decreto/D7024.htm. Acesso em: 06 nov. 2017. 2009b.

Brasil. Ministério do Meio Ambiente.Portaria n 445, de 17 de dezembro de 2014. Diário Oficial da União, Brasília, DF, 18 dez. 2014. Disponível em: http://www.icmbio.gov.br/ cepsul/images/stories/legislacao/Portaria/2014/p_mma_445_2014_lista_peixes_ amea\%C3\%A7ados_extin\%C3\%A7\%C3\%A3o.pdf. Acesso em: 06 nov. 2017. 2014.

Brasil. Lei $\mathrm{n}^{\mathrm{o}}$ 13.266, de 05 de abril de 2016. Extingue e transforma cargos públicos; altera a Lei $\mathrm{n}^{\mathrm{o}} 10.683$, de 28 de maio de 2003, que dispõe sobre a organização da Presidência da República e dos Ministérios, e a Lei $\mathrm{n}^{\mathrm{O}}$ 11.457, de 16 de março de 2007; e revoga dispositivos da Lei nº 10.683, de 28 de maio de 2003. Diário Oficial da União, Brasília, DF, 06 abr. 2016. Disponível em: http://www.planalto.gov.br/ccivil_03/_ato2015-2018/2016/lei/113266. htm. Acesso em: 06 nov. 2017. 2016.

Brasil. Decreto $\mathrm{n}^{\circ}$ 9.004, de 13 de março de 2017. Transfere a Secretaria de Aquicultura e Pesca do Ministério da Agricultura, Pecuária e Abastecimento e a Secretaria Especial da Micro e Pequena Empresa da Secretaria de Governo da Presidência da República para o Ministério da Indústria, Comércio Exterior e Serviços, e dá outras providências. Diário Oficial da União, Brasília, DF, 14 mar. 2017. Disponível em: http:/ /www.planalto.gov.br/ ccivil_03/_ato2015-2018/2017/decreto/D9004.htm. Acesso em: 06 nov. 2017. 2017a.

Brasil. Ministério do Meio Ambiente. Portaria n 161, de 20 de abril de 2017. Diário Oficial da União, Brasília, DF, 24 abr. 2017. Disponível em: http://pesquisa.in.gov.br/imprensa/jsp/ visualiza/index.jspjornal=1\&pagina=79\&data=24/04/2017. Acesso em: 06 nov. 2017. 2017b.

Brasil. Ministério do Meio Ambiente. Portaria $n^{\circ}$ 217, de 19 de junho de 2017. Diário Oficial da União, Brasília, DF, 20 jun. 2017. Disponível em: http://pesquisa.in.gov.br/ 
imprensa/jsp/visualiza/index.jsp?jornal=1\&pagina=54\&data=20/06/2017. Acesso em: 31 jul. 2018. 2017c.

Brasil. Ministério do Meio Ambiente. Retificação. Diário Oficial da União, Brasília, DF, 21 jun. 2017. Disponível em: http:// pesquisa.in.gov.br/imprensa/jsp/visualiza/index.jsp?jo rnal=1\&pagina=44\&data=21/06/2017. Acesso em: 31 jul. 2018. 2017d.

Brasil. Decreto ${ }^{\circ}$ 9.330, de 05 de abril de 2018. Transfere a Secretaria Especial da Aquicultura e da Pesca da Presidência da República para a Secretaria-Geral da Presidência da República, remaneja cargos em comissão e funções de confiança, substitui cargos em comissão do Grupo-Direção e Assessoramento Superiores - DAS por Funções Comissionadas do Poder Executivo - FCPE e altera o Decreto n ${ }^{\circ}$ 9.038, de 26 de abril de 2017, que aprova a Estrutura Regimental e o Quadro Demonstrativo dos Cargos em Comissão e das Funções de Confiança da Secretaria-Geral da Presidência da República. Diário Oficial da União, Brasília, DF, 06 abr. 2018. Disponível em: http://www.planalto.gov.br/ccivil_03/_Ato20152018/2018/Decreto/D9330.htm. Acesso em: 31 jul. 2018. 2018a.

Brasil. Ministério do Meio Ambiente. Portaria n 73, de 26 de março de 2018. Diário Oficial da União, Brasília, DF, 28 mar. 2018. Disponível em: http:/ / pesquisa.in.gov.br/imprensa/ jsp/visualiza/index.jsp?jornal=515\&pagina=160\&data=28/03/2018. Acesso em: 31 jul. 2018. 2018b.

Brasil. Ministério do Meio Ambiente. Portaria n 129, de 27 de abril de 2018. Diário Oficial da União, Brasília, DF, 30 abril. 2018. Disponível em: http:/ / pesquisa.in.gov.br/imprensa/ jsp/visualiza/index.jsp?jornal=515\&pagina $=108 \&$ data $=30 / 04 / 2018$.

Bruckner, A.W. The importance of the marine ornamental reef fish trade in the wider Caribbean. Rev. Biol. Trop. (Int. J. Trop. Biol.), v. 53, n. 1, p. 127-138, 2005.

Gasparini, J.L., Floeter, S.R., Ferreira, C.E.L., Sazima, I. Marine ornamental trade in Brazil. Biodivers. Conserv., v. 14, n. 12, p. 2883-2899, 2005.

Leal, M.C.; Vaz, M.C.M.; Puga, J.; Rocha, R.J.M.; Brown, C.; Rosa, R. \& Calado, R. Marine ornamental fish imports in the European Union: An economic perspective. Fish. Fish., v. 17, n. 2, p. 459-468, 2016.

Magalhães, A.L.B. Presence of prohibited fishes in the Brazilian aquarium trade: effectiveness of laws, management options and future prospects. J. of Appl. Ichthiol., v. 31, n. 1, p. 170-172, 2015.

Monteiro-Neto, C.; Cunha F.E.A.; Nottingham M.C.; Araújo M.E.; Rosa I.L. \& Barros, G.M.L. Analysis of the marine ornamental fish trade at Ceará State, northeast Brazil. Biodivers. Conserv., v. 12, n. 6, p. 1287-1295, 2003.

Mohr, L.V.; Castro, J.W.A.; Costa, P.M.S. \& Alves, R.J.V. Ilhas oceânicas brasileiras: da pesquisa ao manejo - Vol. II. Ministério do Meio Ambiente, 502 p., Brasília, 2009.

Nottingham, M.C.; Barros, G.M.L.; Araújo, M.E.; Rosa, I.M.L.; Ferreira, B.P. \& Mello, T.R.R. O ordenamento da explotação de peixes ornamentais marinhos no Brasil. Bol. Tec. Cient. CEPENE, Tamandaré, v. 13, n. 1, p. 75-107. 2005.

Prakash, S.; Kumar, T.T.A.; Raghavan, R.; Rhyne, A.; Tlusty, M.F. \& Subramoniam, T. Marine aquarium trade in India: challenges and opportunities for conservation and policy. Mar. Policy, v. 77, p. 120-129, 2017. 
Reynoso, F.L.; Castañeda-Chávez, M.; Zamora-Castro, J.E.; Hernández-Zárate, G.; RamírezBarragán, M.A. \& Solís-Morán, E. La acuariofilia de especies ornamentales marinas: un mercado de retos y oportunidades. Lat. Am. J. Aquat. Res., v. 40, n. 1, p. 12-21, 2012.

Rhyne, A.L.; Tlusty, M.F. \& Kaufman, L. Is sustainable exploitation of coral reefs possible? A view from the stand point of the marine aquarium trade. Curr. Opin. Environ. Sustainability, v. 7, p. 101-107, 2014.

Rhyne, A.L.; Tlusty, Szczebak, J.T. \& Robert J. Holmberg, R.J. Expanding our understanding of the trade in marine aquarium animals. PeerJ, v. 5, (doi:10.7717/peerj.2949, e2949), 2017.

Rosa, I.L.; Oliveira, T.P.R.; Osório, F.M.; Moraes, L.E.; Castro, A.L.C.; Barros, G.M.L. \& Alves, R.R.N. Fisheries and trade of seahorses in Brazil: historical perspective, current trends, and future directions. Biodivers. Conserv., v. 20, n. 9, p. 1951-1971, 2011.

Sampaio, C.L.S. \& Nottingham, M.C. Guia para identificação de peixes ornamentais brasileiros - Espécies marinhas - Volume I. Ministério do Meio Ambiente, 205 p., Brasília, 2008.

Sampaio, F.D.F. \& Ostrensky, A. Brazilian environmental legislation as tool to conserve marine ornamental fish. Mar. Policy, v. 42, p. 280-285, 2013.

Sátyro, P.B. Surgimento, evolução e divisão do Ibama. Monografia de Graduação, Curso de Engenharia Florestal do Instituto de Florestas, Universidade Federal Rural do Rio de Janeiro, 24 p., Seropédica, 2008.

Tissot, B.N.; Best, B.A; Borneman, E.; Bruckner, A.W.; Cooper, C.H.; D’ Agnes, H.; Fitzgerald, T.P ; Leland, A.; Lieberman S.; Amos, A.M.; Sumaila, R.; Telecky, T.M.; McGilvray, F.; Plankis, B.J.; Rhyne, A.L.; Roberts, G.G.; Starkhouse, B. \& Stevenson, T.C. How US ocean policy and market power can reform the coral reef wildlife trade. Mar. Policy, v. 34, p. 1385-1388, 2010.

Wabnitz, C.; Taylor, M.; Green, E. \& Razak, T. From Ocean to Aquarium. UNEP-WCMC, 66 p., Cambridge, 2003.

Whittington, R.J. \& Chong, R. Global trade in ornamental fish from an Australian perspective: The case for revised import risk analysis and management strategies. Prev. Vet. Med., v. 81, n. 1-3, p. 92-116, 2007.

Wood, E. Collection of coral reef fish for aquaria: global trade, conservation issues and management strategies. Marine Conservation Society, 56 p., Ross-on-Wye, 2001. 
